\title{
Biblical Influences on Conservation: an Examination of the Apparent Sustainability of Kosher Seafood
}

\author{
Phillip S. Levin ${ }^{1}$, Joel Azose ${ }^{2}$ and Sean Anderson ${ }^{3}$
}

\begin{abstract}
As a response to widespread concern about the state of marine ecosystems and the perceived failure of existing policies, many organizations are developing market-based instruments that promote sustainability. Eco-standards such as shopping guides, ecolabels, and stewardship certifications are now commonplace. However, in many cultures dietary guidelines have existed for thousands of years, and anthropologists have argued that such dietary rules emerged to reduce environmental impacts by encouraging exploitation of productive species, increasing ecological efficiency, or decreasing harvest of apex predators. We explored some of the environmental consequences for marine and aquatic systems of one of the more familiar ancient dietary traditions, keeping kosher. We sampled nearly 4500 seafood items from 68 supermarkets and 112 restaurants. For each species, we determined whether the item was kosher or not and then estimated trophic level, food miles, energy consumption, and carbon dioxide emissions. Our results revealed that food miles, energy consumption, and $\mathrm{CO}_{2}$ emissions associated with transportation were all less for kosher than nonkosher seafood. In general, these differences could be mitigated by consuming only Monterey Bay Aquarium Seafood Watch "best" choices. On the other hand, although food miles, energy consumption, and carbon dioxide emissions associated with kosher seafood appears to be lower than nonkosher seafood, the potential trophic impact of kosher seafood appears to be greater than nonkosher selections. Our results highlight that even though the moral underpinnings of conservation and religion can be very different, careful scientific attention to the environmental costs and benefits of traditional foodways offers an important entry point for engagement with cultural practices and belief systems.
\end{abstract}

Key Words: carbon footprint; conservation; eco-label; kosher; marine conservation; religion; sustainability

\section{INTRODUCTION}

As a response to widespread concerns about the state of the environment and the perceived failure of existing policies to mitigate environmental threats, many organizations are developing market-based instruments that promote sustainability. Eco-standards such as shopping guides, eco-labels, and stewardship certifications are now commonplace. Eco-labeling of a wide range of products and services is an increasing practice, which may serve to educate consumers about the environmental impact of their behavior and empower consumers to change their behavior in a way that reduces negative environmental impacts (Boström and Klintman 2008). The growth of eco-labeling has been rapid. For example, products labeled as 'organic' experienced recent growth rates exceeding $20 \%$ annually, and 'fair trade' labels have exhibited annual growth rates exceeding 100\%. Eco-labeling of seafood is also expanding (Howard and Allen 2010). As examples: (1) the Marine Stewardship Council's eco-label was established in 1997 and now is on over 12,000 seafood products (Goyert et al. 2010, Monterey Bay Aquarium 2011), and (2) the Monterey Bay Aquarium has distributed more than 40 million Seafood Watch wallet cards and has had 1 million downloads of their smartphone application, which identify sustainable seafood options (Monterey Bay Aquarium 2011).

Currently there are dozens of eco-labeling schemes for seafood (Goyert et al. 2010), but the efficacy of eco-standards and ecolabeling of seafood products is a topic of increasing debate (Teisl et al. 2002, Jacquet et al. 2010, Froese and Proelß 2012). For ecolabeling to be effective, consumers must have an environmental ethic and be willing to pay a price premium associated with ecolabeling (Kaiser and Edward-Jones 2006, Sønderskov and
Daugbjerg 2011). The evidence suggesting that these conditions are met is often weak. For example, in a survey of 305 consumers, Goyert et al. (2010) reported that price, freshness, and taste were the most important factors when deciding whether to purchase Maine lobster. Less than $1 \%$ of respondents identified harm to the ocean environment, overfishing, or distance shipped as important factors. In addition, accuracy about the sustainability of seafood products is notoriously poor (Kaiser and EdwardJones 2006), and different eco-labeling programs will often reach very different conclusions about the sustainability of the same fish stock (Christian et al. 2013). Moreover, in the United States, for instance, more than one-third of seafood is mislabeled, and a lack of traceability allows suppliers to sell mislabeled, unsustainable seafood as an eco-friendly species (Jacquet and Pauly 2008). More broadly, an independent investigation of ecolabels making general claims revealed that $56 \%$ of the labels were 'not meaningful' (Starobin and Weinthal 2010).

Eco-standards and labeling may be viewed together as a modern example of the social, political, and psychological influences that affect food choices (Imai et al. 2009). Indeed, patterns of food consumption are a language through which a society expresses itself (Soler 1997), and the labeling of food for ecological, social, or health reasons is a practice deeply rooted in a number of cultures (Jordan et al. 2004). The Hua of Papua New Guinea, for instance, have hundreds of criteria as to what can and cannot be consumed. Food is so central to the Hua that their word for 'everything' translates literally into "that which can be eaten and that which cannot" (Meigs 1987). In developed countries, Muslim consumers rely on food labels to verify the authenticity of halal food (Bonne and Verbeke 2008). Similarly, food labels

\footnotetext{
${ }^{1}$ NOAA Fisheries, Northwest Fisheries Science Center, ${ }^{2}$ NOAA Fisheries, Northwest Fisheries Science Center, Conservation Biology Division,

${ }^{3}$ Environmental Science and Resource Management Program, California State University Channel Islands
} 
documenting the lack of genetic modification are important to Seventh-day Adventists and Buddhists, among others, who are vegetarians and object to the presence of animal genes in their food (Brunk and Coward 2009).

One of the better-known cultural food customs is the practice of keeping kosher. Kashrut is the body of Jewish law dealing with what foods Jews can and cannot eat, and how these foods must be prepared and eaten. Kosher describes foods that meet the standards of Kashrut. Kosher practices are built on a set of biblically based rules that are complex, extensive, and focus on the type of foods consumed, the processing and handling of food, and the equipment used to prepare the food (Stern 2004). Packaged products certified as kosher are labeled with a 'hechsher, 'a symbol to indicate that a certifying organization has supervised the production and that all ingredients used in the product are kosher.

The core of modern kashrut is articulated in Leviticus, chapter 11 and Deuteronomy, chapter 14, which are devoted to the distinction between 'clean' and 'unclean' species (Soler 1997). These texts address the appropriateness of terrestrial mammals, birds, insects, and marine/aquatic species for consumption. For instance, mammals must be ruminates with cloven hooves (Leviticus 11:3); marine species must have fins and scales (Leviticus 11:9), and flying insects must have jointed legs for hopping on the ground, e.g., locusts (Leviticus 11:21-22). The origin of the laws of kashrut are not obviously linked to environmental issues (Welfeld 1996); nonetheless, contemporary Jews have made the link (Gerstenfeld 1998).

Because dietary guidelines, whether they are based on religious or environmental principles, influence consumer behavior, these guidelines often have collateral or unintended consequences (Boström and Klintman 2008). Certification of wood products by the Forest Stewardship Council, for instance, led to the proliferation of other certification schemes, including the Marine Stewardship Council for seafood certification (Auld et al. 2008). In the case of religious practices, consumers of kosher land mammals may be exposed to lower levels of naturally occurring toxins than individuals who consume nonkosher meat (Macht 1953). On the other hand, consumers of poultry slaughtered following kosher methods are potentially exposed to greater levels of Salmonella (Clouser et al. 1995) because of the methods used for defeathering.

Are there are collateral environmental costs or benefits of consuming kosher seafood? In essence, we ask if kashrut serves as an accidental eco-label. Using information derived from a survey of 68 supermarkets and 112 restaurants, we ask if (1) the carbon footprint associated with the transport step of the seafood production lifecycle differs between kosher seafood and nonkosher seafood species; and (2) if the potential impact on aspects of ecosystem structure or function varies between kosher and nonkosher seafood.

\section{METHODS}

In 2007, we surveyed 68 supermarkets and 112 restaurants in Santa Barbara, Ventura, and Los Angeles counties that served at least 1 seafood item. We sampled a total of 2171 seafood items from supermarkets and 2321 items from restaurants. For simplicity, we focused our efforts on wild-caught seafood. Details of sampling methods can be found in Anderson (2010).
At each supermarket and restaurant, we sampled the apparent species identity, price, fishing or aquaculture method, collection location, brand, processor location, seafood species, and any other relevant descriptors. These were gathered for each available seafood item (Anderson 2010). In some instances, desired information was lacking on labels or menus. In these cases, fishmongers or wait staff were asked to provide the additional missing information. Unless there was an obvious inaccuracy in the reported data, all reported information was assumed to be correct for purposes of this study (Anderson 2010).

\section{ESTIMATING SELECTED COMPONENTS OF SUSTAINABILITY}

\section{Aspects of carbon footprints}

Food miles is a simple, though incomplete, indicator of gross environmental impact of the food supply chain (Weber and Matthews 2008). We used the food miles estimated by Anderson (2010). Efforts to quantify food miles usually focus on characterizing the average of all items of a particular food category arriving at a given location, weighted by the amount of food items in each category (Carlsson-Kanyama 1997). Because Anderson (2010) did not have the sales volume of each particular seafood item, he calculated the distance traveled for each item and then averaged these distances. Distances were measured as orthodromic distances from the geographic midpoint of a particular region or from a county or region's largest major harbor to Ventura, California. These estimates are minimums because they ignore aspects of the food supply chain, e.g., capture method, shipping route, and processor location.

Because mode of transportation varies with location and the immediacy of getting the particular item to the consumer, Anderson (2010) elicited information from seafood wholesalers and importers to partition transportation modes among air, rail, ship, etc. Using information on distance and transportation mode, it is possible to generate estimates of energy consumption and emissions (Anderson 2010).

Importantly, transportation is only part of the total carbon footprint of seafood production. For instance, for capture fisheries harvest, method can be an important component of carbon footprint. Similarly, for aquaculture, feed production and outgrowth will also contribute to the carbon footprint. The results we present characterize only the transportation phase of the seafood production lifecycle; however, our objective is not to completely characterize the carbon footprint of seafood production. Rather, our aim is to take a first step at exploring the potential impact of cultural or religious practices on some aspects of sustainability.

\section{TROPHIC LEVEL}

Trophic level has become a pervasive indicator used to measure the integrity of marine ecosystems, especially those dominated by exploited species (Pauly et al. 1998, Essington et al. 2006, Levin and Dufault 2010). Conceptually, trophic level is linked to topdown control and trophic cascades in ecological communities; a decline in the mean trophic level in an ecosystem may suggest a reduction in the ability of predators to 'control' prey populations and may have far-reaching consequences to ecological communities. Theoretical modeling suggests that mean trophic level can be a good indicator of fishing effects on an ecosystem (Fulton et al. 2005, Samhouri et al. 2009). 
We used Fishbase (http://www.fishbase.org/search.php) and Field et al. (2006) to estimate the trophic level of each of the seafood items we sampled. Supplemental materials provided trophic level by species for market and restaurant items.

\section{MONTEREY BAY AQUARIUM SEAFOOD WATCH PROGRAM}

The Monterey Bay Aquarium launched the Seafood Watch program in 2000 in an effort to provide a simple tool that aquarium visitors and seafood consumers could use to identify environmentally sustainable seafood (Kemmerly and Macfarlane 2009). The Seafood Watch program incorporates five basic principles: (1) low vulnerability to fishing pressures, (2) stock structure sufficient to maintain productivity, (3) minimization of bycatch, (4) maintenance of ecosystem function, and (5) a functional management regime. These principles are incorporated into a red-yellow-green rating system. Details of the Seafood Watch recommendation process are available from Seafood Watch 2012. We assigned each of the 4492 seafood items we sampled to one of the three Seafood Watch categories using the program's online guide available at http://www. seafoodwatch.org. We selected the Seafood Watch program for this analysis because it is widely known (Shelton 2009), has broad geographic coverage, and transparently identifies sustainable as well as unsustainable species.

\section{DATA ANALYSIS}

We used t-tests to test the null hypotheses that food miles, energy consumed, carbon dioxide emissions, and the trophic level of kosher seafood did not differ from that of nonkosher seafood. We used the standards of the Orthodox Union (available from $\underline{h t p}$ :// www.kashrut.com/articles/fish/) to classify seafood as kosher or nonkosher.

To examine the sustainability of seafood as defined by the Seafood Watch program, we first simply examined the proportion of kosher and nonkosher seafood items that were classified as "avoid," "good," and "best" by Seafood Watch. In some cases, Seafood Watch provided a range of ratings for the same species, depending on location or method of capture; therefore, we conducted analyses with both ratings that were optimistic, i.e., the highest possible rating, or pessimistic, i.e., the lowest possible rating.

We next asked how food miles, energy consumption, and $\mathrm{CO}_{2}$ emissions would compare if individuals randomly selected a kosher versus nonkosher seafood item. We then asked if any differences between kosher versus nonkosher seafood items would be reduced if a consumer only purchased Seafood Watch "best" choices. To accomplish this, we used a bootstrapping procedure as follows. We first calculated the relative proportion of each species in each of four categories, i.e., kosher and nonkosher species sampled in restaurants and kosher and nonkosher species sampled in seafood markets. Then, we randomly sampled the data set 100 times (with replacement) with weighted probabilities for selecting a specific species equal to relative proportions and generated a mean from these 100 samples. We repeated this process 1000 times generating a distribution of food miles, energy consumption, and $\mathrm{CO}_{2}$ emissions. This allowed us to determine the proportion of times a random kosher item would have a greater transportation-associated carbon footprint rather than a random nonkosher item. We then repeated this procedure using only "best" choice Seafood Watch items (kosher or nonkosher) and compared them to randomly selected kosher seafood. We used only the "optimistic" rating for this analysis.

\section{RESULTS}

The transportation-associated carbon footprint associated with kosher seafood in both seafood markets and restaurants was less than that of nonkosher seafood (Fig. 1). The average kosher seafood item sold in markets traveled a significantly shorter distance $(\sim 2000 \mathrm{~km})$ than a nonkosher seafood item $(\mathrm{t}=14.90$, df 2226, $\mathrm{p}<0.001)$. Similarly, kosher seafood from restaurants traveled ca. $1200 \mathrm{~km}$ less than nonkosher items $(\mathrm{t}=10.35$, df 1359 , $\mathrm{p}<0.001)$. Consequently, the mean energy consumed in the transportation of kosher seafood sold in seafood markets was about $78 \%$ of that for nonkosher items $(\mathrm{t}=6.51$, df 2226 , $\mathrm{p}<$ 0.001 ), and in restaurants, energy consumption was about $71 \%$ of that of nonkosher seafood $(\mathrm{t}=10.14$, df 1359, $\mathrm{p}<0.001)$. Likewise, $\mathrm{CO}_{2}$ emissions associated with kosher seafood were $79 \%$ and $71 \%$ of that of nonkosher items sampled from markets and restaurants, respectively (markets, $\mathrm{t}=6.47$, df 2226, $\mathrm{p}<0.001$; restaurants, $\mathrm{t}=10.13$, df $1359, \mathrm{p}<0.001)$.

Fig. 1. Estimated average food distance, energy consumption, carbon dioxide emissions, and trophic level of 4492 kosher and nonkosher seafood items sampled from markets and restaurants in Southern California. Food distances were measured as orthodromic distances from the geographic midpoint of a particular region or from a county's or region's largest major harbor to Ventura, California. Energy consumption and carbon dioxide emissions are based on food distance as well as information from seafood venders regarding transportation modes, e.g., air, rail, or ship. Our estimates do not include harvest or processing method.
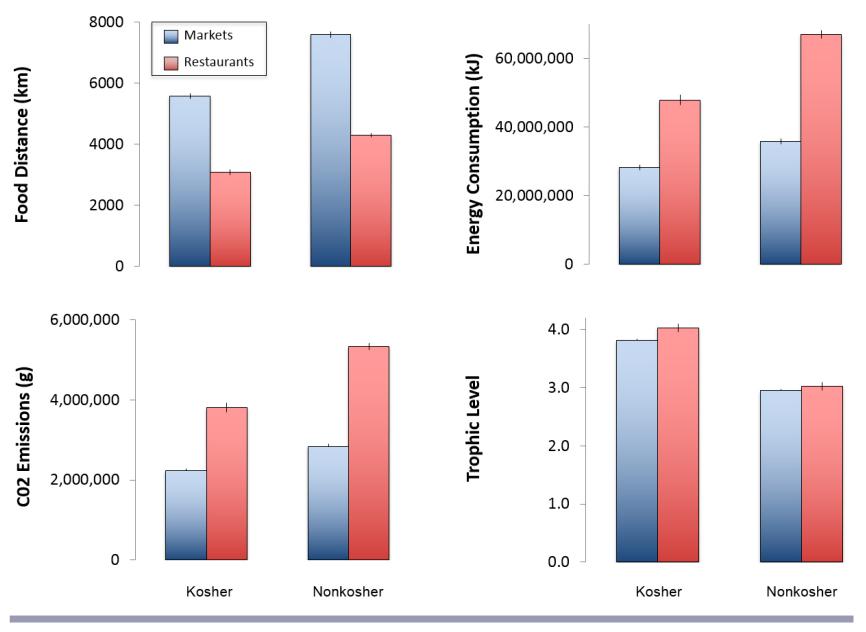

The proportion of seafood items that were classified as "avoid," "good," and "best" by Seafood Watch also differed between kosher and nonkosher items (Table 1). When we examined seafood sampled in markets, we found that about twice as many kosher items fell in the "best" Seafood Watch category compared to nonkosher items. However, when we looked at seafood from restaurants, the pattern reversed, the "best" category was dominated by nonkosher items. Large differences in the "good" 
Table 1. The proportion of seafood items that were classified as "avoid," "good," and "best" by Monterey Bay Aquarium's Seafood Watch program. Ambiguity in the point-of-sale species identification (e.g., "tuna"), harvest method (e.g., no information provided), or geographic origin (e.g., Atlantic) or ambiguity in the guideline categories (e.g., U.S. farmed cobia, Rachycentron canadum = best choice, but imported farmed cobia $=$ avoid) lead to a spectrum of possible decisions for a given seafood item. We show results here based on both optimistic (the highest possible rating) and pessimistic (lowest possible rating) assumptions.

\begin{tabular}{|c|c|c|c|c|c|c|}
\hline \multirow[t]{2}{*}{ Seafood Source } & \multirow{2}{*}{$\begin{array}{l}\text { Seafood Watch } \\
\text { Interpretation }\end{array}$} & \multirow{2}{*}{$\begin{array}{l}\text { Kosher } \\
\text { Status }\end{array}$} & \multicolumn{4}{|c|}{ Seafood Watch Category } \\
\hline & & & Avoid & Good & Best & Unknown \\
\hline \multirow[t]{4}{*}{ Market } & Optimistic & Kosher & 0.13 & 0.13 & 0.29 & 0.02 \\
\hline & & Nonkosher & 0.13 & 0.11 & 0.17 & 0.02 \\
\hline & Pessimistic & Kosher & 0.31 & 0.07 & 0.13 & 0.06 \\
\hline & & Nonkosher & 0.20 & 0.09 & 0.06 & 0.08 \\
\hline \multirow[t]{4}{*}{ Restaurant } & Optimistic & Kosher & 0.03 & 0.08 & 0.20 & 0.06 \\
\hline & & Nonkosher & 0.03 & 0.07 & 0.50 & 0.03 \\
\hline & Pessimistic & Kosher & 0.24 & 0.02 & 0.03 & 0.07 \\
\hline & & Nonkosher & 0.40 & 0.12 & 0.05 & 0.06 \\
\hline
\end{tabular}

category were not evident, with the exception of the pessimistic restaurant grouping in which we observed substantially more nonkosher than kosher items. Finally, a consistent pattern in the "avoid" category did not emerge. When we used "optimistic" groupings, we saw no difference between kosher and nonkosher items. However, when we used "pessimistic" groupings, we observed more "avoid" kosher items in markets and more "avoid" nonkosher selections in restaurants.

We next asked if individuals randomly selected a kosher versus nonkosher seafood item, would the transportation-associated carbon footprint differ. The likelihood of a random kosher seafood item from a market traveling less distance than a similarly selected nonkosher item was $66.95 \% \quad(95 \%$ CI $0.34 \%)$. Consequently, the chance that a random nonkosher seafood item would use more energy in transport than a kosher item was $58.94 \%$ $(95 \% \mathrm{CI} 0.33 \%)$, and that it would generate more $\mathrm{CO}_{2}$ was $58.31 \%$ $(95 \%$ CI $0.36 \%)$. Similarly, the likelihood of a random kosher seafood item selected at a restaurant traveling less distance than a similarly selected nonkosher item was $68.03 \%$ (95\% CI $0.33 \%$ ). Thus, the chance that a random nonkosher seafood item from a restaurant would use more energy in transport than a kosher item was $66.62 \%(95 \% \mathrm{CI} 0.33 \%)$, and that it would generate more $\mathrm{CO}_{2}$ was $66.94 \%(95 \%$ CI $0.33 \%)$.

Finally, when we compared the transportation-associated carbon footprint of randomly selected kosher seafood vs. a randomly selected Seafood Watch "best" choice (either kosher or nonkosher), the differences we described above were eliminated. The likelihood of a random kosher seafood item from restaurants traveling less distance than a Seafood Watch "best" item was $51.11 \%$ (95\% CI 0.35). Consequently, the chance that a random Seafood Watch "best" selection would use more energy in transport than a kosher item was $46.09 \%$ (95\% CI $0.36 \%)$, and that it would generate more $\mathrm{CO}_{2}$ was $45.98 \%$ (95\% CI $0.35 \%$ ). The likelihood of a random kosher seafood from markets traveling less distance than a Seafood Watch "best" selections was $30.46 \% \%$ (95\% CI 0.33). Thus, the chance that a random Seafood Watch "best" selection would use more energy in transport than a kosher item was $38.37 \%$ (95\% CI $0.34 \%)$, and that it would generate more $\mathrm{CO}_{2}$ was $38.17 \%$ (95\% CI $\left.0.35 \%\right)$.

In contrast to the carbon footprint results, when we examined the potential trophic impact of kosher vs. nonkosher seafood, the environmental impact of kosher seafood may be greater (markets, $\mathrm{t}=29.91$, df 2226, $\mathrm{p}<0.001$; restaurants, $\mathrm{t}=38.68$, df $1359, \mathrm{p}<$ 0.001). In seafood sampled in markets, the trophic level of nonkosher seafood averaged 2.95 (SE 0.018), whereas kosher seafood averaged 3.81 (SE 0.020). In restaurants, the mean trophic level of nonkosher seafood was 3.02 (SE 0.016), whereas kosher seafood averaged 4.03 (SE 0.02).

\section{DISCUSSION}

For millennia, merchant behavior has been subjected to consumer norms and nongovernmental practices. Indeed, Braithwaite and Drahos (2000) argued that the early Christian church was the first organization to supply a set of norms that regulated transnational business. And, as we discussed, the classification of food in compliance with edicts associated with Jewish, Muslim, or other religions is a clear example of ancient food certification (Webb 2002). We explored the degree to which such norms or standards inadvertently influenced some conservation outcomes. Our results revealed that food miles, energy consumption, and $\mathrm{CO}_{2}$ emissions associated with transportation were all less for kosher than nonkosher seafood. In general, these differences could be mitigated by consuming only Seafood Watch "best" choices, as these tended to have lower food miles than "poor" choices. On the other hand, although the transportation-associated carbon footprint associated with kosher seafood appears to be lower than nonkosher seafood, the potential trophic impact of kosher seafood appears to be greater than nonkosher selections.

The patterns we observed were heavily influenced by the dominant species in the U.S. seafood marketplace, i.e., shrimp and salmon. About $13 \%$ of seafood items we sampled in markets and $21 \%$ of the restaurant items were shrimp. As a crustacean, shrimp are not kosher. We estimated the average distance traveled by shrimp as 5673 kilometers to restaurants and 10,290 kilometers to markets. 
We speculated that the difference between market and restaurants is related to a prevalence of fresh vs. frozen shrimp in restaurants. In contrast, some $13 \%$ of the market items and $9 \%$ of restaurant selections were (kosher) salmon, and their food miles varied between $1100 \mathrm{~km}$ and $3500 \mathrm{~km}$, depending on species. The median distance of items we sampled was $3739 \mathrm{~km}$.

Our estimates of the carbon footprint of fisheries focused solely on food miles and are thus clearly only an approximation of a portion of the seafood production lifecycle. Importantly, different fisheries vary greatly in their fuel consumption during harvest (Pelletier et al. 2011), and this was not captured in our analysis. For instance, purse seine fisheries in the North Atlantic for low trophic level fishes such as Atlantic herring, Gulf menhaden, and Blue whiting burn between 0.021 and $0.140 \mathrm{~kg}$ fuel per $\mathrm{kg}$ fish (Tyedmers and Parker 2012). Purse seining for higher trophic level species generally has higher fuel consumption. For example, purse seining skipjack or yellowfin tuna uses $0.368 \mathrm{~kg}$ of fuel per $\mathrm{kg}$ of landed fish (Tyedmers and Parker 2012). Trawling is generally less fuel-efficient than purse seining. For instance, shrimp trawlers in Norway consume $1.04 \mathrm{~kg}$ of fuel $/ \mathrm{kg}$ fish, i.e., about two orders of magnitude greater than purse seines in the same system (Schau et al. 2009). Because of the diversity of fisheries included in our samples, it was difficult to know precisely how the addition of this level of detail would affect our results. However, given the importance of shrimp in our results and the high fuel use of shrimp fisheries worldwide (Tyedmers 2004), our conclusions are likely robust to among-fisheries differences in fuel consumption. Similarly, our work did not address differences in carbon footprints associated with aquaculture practices.

Another key caveat in our analysis is that estimates of food miles will vary based on geography. However, because about $75 \%$ of the shrimp imported into the U.S. originates in Asia (FAO 2012), and more than $95 \%$ of wild salmon in the U.S. marketplace are captured in Alaska (Irvine et al. 2010), qualitatively our conclusions are likely reasonable for the U.S. That is, the relative distance between different US locations and Asia and Alaska means that location within the US will not alter that general pattern we report.

There is a clear difference in the trophic levels represented by kosher and nonkosher seafood. Of the 56 seafood items we sampled that were below trophic level 3, only $21 \%$ were kosher. On the other hand, about $85 \%$ of the 59 species that were above trophic level 4 were kosher. The lower trophic level of nonkosher seafood was exemplified by shrimp with a trophic level of 2.75 . In contrast, salmon, the most common kosher item, had a trophic level of about 4.06. The negative effects on ecosystem structure and function resulting from the removal of high trophic level marine species is well known (Baum and Worm 2009, Estes et al. 2011), and thus there is a potential that the food web impact of consuming kosher fish is greater than that of nonkosher items. Of course, definitively addressing this question requires additional empirical or theoretical research, which takes into account species distribution, abundance, diets, and functional responses (Ainsworth et al. 2012). Interestingly, the rules of kashrut prohibit eating of terrestrial predators (Stern 2004); thus, this type of potential trophic impact of kosher consumption is uniquely marine.

We addressed the potential collateral environmental costs or benefits of consuming kosher seafood. In a sense, we asked if the kosher designation was an accidental eco-label. To be successful in achieving conservation aims, eco-labels require some degree of political mobilization (Steinberg 2009). In the framework of Hirschman (1970), consumers could promote conservation by first 'exiting' consumption of unsustainable fisheries through their economic choices, and second, by 'voicing' support for rules or policies that they find desirable. Unlike the case with eco-labels, however, kosher, halal, or other dietary prescriptions do not require direct consumer action to affect conservation outcomes because the motivation underlying such guidelines is unrelated to conservation. Eco-labels inform consumers so they can identify and buy sustainable seafood while also sending a signal to policy makers through their economic behavior (Howard and Allen 2010); however, in many cases the political motivation of the general populous toward eco-labels is low (Gulbrandsen 2006), and the penetration of eco-labels in the market place is poor (Washington 2008). Additionally, as is revealed in Table 1, information provided by eco-labels can be ambiguous and difficult to interpret. Thus, despite the increase of eco-labeling schemes, the near-term impacts of these efforts on conservation outcomes may be limited (Gullison 2003, Washington 2008, Blackman and Rivera 2011). On the other hand, as we have shown here, the collateral impacts of dietary practices may be significant, but do not require the same sort of political impetus.

As appears to be the case for kosher seafood, a number of religious or social rituals appear to inadvertently influence, positively or negatively, conservation outcomes. For instance, in Oceania, a number of traditional practices inadvertently affected the conservation of marine resources. These included restricting the eating of some foods to certain social classes, sexes, or clans; prohibiting fishing on the death of an important individual; and prohibiting women from particular types of fishing (McNeely and Pitt 1985). Apparently, such practices did have a positive impact on local environments (McNeely and Pitt 1985), although reviving or reinforcing practices based on gender or social class is obviously problematic. In Kalimantan, Indonesia, the tembawang fruit gardens serve as a sacred burial ground with highly restricted access. Because the landscape of the region is heavily modified, the gardens, with some 400 plant species, are the main repository of regional biodiversity (Marjokorpi and Ruokolainen 2003). In contrast, releases of captive animals associated with Buddism and Taoism have led to the dispersal of invasive species with the concomitant negative impacts on recipient communities (Agoramoorthy and Hsu 2005). Bullfrogs, for instance, are frequently the objects of ceremonial releases in Yunnan Provence, China, which has led to their establishment at the expense of native amphibians (Liu et al. 2012).

Conservation is often driven by faith-based values (Bhagwat et al. 2011a); however, evidence demonstrating that individuals associated with religions are more concerned about the environment than those who are not is generally lacking (Bhagwat et al. 2011b). Nonetheless, some theologians have argued that reframing and reinvigorating traditional practices can be an important component of natural resource management (Palmer and Finlay 2003). Palmer (2010) contended that cultures could enhance sound ecological dietary principles by building them into rituals that are sanctioned by faith and maintained by social pressure. This notion is amplified by Awoyemi et al. (2012) because they noted that individuals are inclined to contribute to conservation efforts if they confer prestige and are socially 
significant. Thus, even though the moral underpinnings of conservation and religion can be very different (Adams et al. 2004), careful scientific attention to the environmental costs and benefits of traditional foodways offers an important entry point for engagement with cultural practices and belief systems.

Responses to this article can be read online at: http://www.ecologyandsociety.org/issues/responses. $\mathrm{php} / 6524$

\section{Acknowledgments:}

We express our extreme thanks to California State University Channel Islands Coastal and Marine Management Class for assisting with data collection. The thoughtful comments of M. Ford, $K$. Norman, and M. Poe are greatly appreciated. Members of Congregation Beth Shalom provided critical discussion that sharpened our thinking. We thank G. Gallus for inspiration and distraction.

\section{LITERATURE CITED}

Adams, W. M., R. Aveling, D. Brockington, B. Dickson, J. Elliott, J. Hutton, D. Roe, B. Vira, and W. Wolmer. 2004. Biodiversity conservation and the eradication of poverty. Science 306:1146-1149.

Agoramoorthy, G., and M. J. Hsu. 2005. Religious freeing of wildlife promotes alien species invasion. Bioscience 55:6. http:// dx.doi.org/10.1641/0006-3568(2005)055[0006:RFOWPA]2.0.CO;2

Ainsworth, C. H., H. N. Morzaria Luna, I. C. Kaplan, P. S. Levin, and E. A. Fulton. 2012. Full compliance with harvest regulations yields ecological benefits: Northern Gulf of California case study. Journal of Applied Ecology 49:63-72. http://dx.doi.org/10.1111/ j.1365-2664.2011.02064.x

Anderson, S. 2010. Access to sustainable seafood in Southern California (USA): globalized delivery, moderate price increases, but limited knowledge and choice. Pacific Institute for Restoration Ecology Report \#2010-04. California State University, Environmental Science and Resource Management, Camarillo, California, USA.

Auld, G., L. H. Gulbrandsen, and C. L. McDermott. 2008. Certification schemes and the impacts on forests and forestry. Annual Review of Environment and Resources 33:187-211. http:// dx.doi.org/10.1146/annurev.environ.33.013007.103754

Awoyemi, S. M., A. Gambrill, A. Ormsby, and D. Vyas. 2012. Global efforts to bridge religion and conservation are they really working. Pages 953-978 in T. Povilitis, editor. Topics in conservation biology. In Tech, Rijeka, Croatia,

Baum, J. K., and B. Worm. 2009. Cascading top-down effects of changing oceanic predator abundances. Journal of Animal Ecology 78:699-714. http://dx.doi.org/10.1111/j.1365-2656.2009.01531. $\underline{x}$

Bhagwat, S. A., N. Dudley, and S. R. Harrop. 2011a. Religious following in biodiversity hotspots: challenges and opportunities for conservation and development. Conservation Letters 4:234-240. http://dx.doi.org/10.1111/j.1755-263X.2011.00169.x

Bhagwat, S. A., A. A. Ormsby, and C. Rutte. 2011b. The role of religion in linking conservation and development: challenges and opportunities. Journal for the Study of Religion, Nature and Culture 5:39-60.

Blackman, A., and J. Rivera. 2011. Producer-level benefits of sustainability certification. Conservation Biology 25:1176-1185. http://dx.doi.org/10.1111/j.1523-1739.2011.01774.x

Bonne, K., and W. Verbeke. 2008. Religious values informing halal meat production and the control and delivery of halal credence quality. Agriculture and Human Values 25:35-47. http://dx.doi. org/10.1007/s10460-007-9076-y

Boström, M., and M. Klintman. 2008. Eco-standards, product labelling and green consumerism. Palgrave Macmillan, New York, New York, USA. http://dx.doi.org/10.1057/9780230584006

Braithwaite, J., and P. Drahos. 2000. Global business regulation. Cambridge University Press, Cambridge, UK.

Brunk, C. G., and H. Coward. 2009. Acceptable genes? Religious traditions and genetically modified foods. State University of New York Press, Albany, New York, USA.

Carlsson-Kanyama, A. 1997. Weighted average source points and distances for consumption origin-tools for environmental impact analysis? Ecological Economics 23:15-23. http://dx.doi. org/10.1016/S0921-8009(97)00566-1

Christian, C., D. Ainley, M. Bailey, P. Dayton, J. Hocevar, M. LeVine, J. Nikoloyuk, C. Nouvian, E. Velarde, R. Werner, and J. Jacquet. 2013. A review of formal objections to Marine Stewardship Council fisheries certifications. Biological Conservation 161:10-17. http://dx.doi.org/10.1016/j.biocon.2013.01.002

Clouser, C. S., S. J. Knabel, M. G. Mast, and S. Doores. 1995. Effect of type of defeathering system on Salmonella crosscontamination during commercial processing. Poultry science 74:732-741. http://dx.doi.org/10.3382/ps.0740732

Essington, T. E., A. H. Beaudreau, and J. Wiedenmann. 2006. Fishing through marine food webs. Proceedings of the National Academy of Sciences 103:3171-3175. http://dx.doi.org/10.1073/ pnas.0510964103

Estes, J. A., J. Terborgh, J. S. Brashares, M. E. Power, J. Berger, W. J. Bond, S. R. Carpenter, T. E. Essington, R. D. Holt, J. B. C. Jackson, R. J. Marquis, L. Oksanen, T. Oksanen, R. T. Paine, E. K. Pikitch, W. J. Ripple, S. A. Sandin, M. Scheffer, T. W. Schoener, J. B. Shurin, A. R. E. Sinclair, M. E. Soulé, R. Virtanen, and D. A. Wardle. 2011. Trophic downgrading of Planet Earth. Science 333:301-306. http://dx.doi.org/10.1126/science.1205106

Food and Agriculture Organization (FAO). 2012. Globefish: shrimp U.S. - March 2012. Food and Agriculture Organization, Rome, Italy. [online] URL: http://www.globefish.org/shrimp-usmarch-2012.html

Field, J. C., R. C. Francis, and K. Aydin. 2006. Top-down modeling and bottom-up dynamics: linking a fisheries-based ecosystem model with climate hypotheses in the Northern 
California Current. Progress in Oceanography 68:238-270. http:// dx.doi.org/10.1016/j.pocean.2006.02.010

Froese, R., and A. Proelß. 2012. Evaluation and legal assessment of certified seafood. Marine Policy 36:1284-1289. http://dx.doi. org/10.1016/j.marpol.2012.03.017

Fulton, E. A., A. D. M. Smith, and A. E. Punt. 2005. Which ecological indicators can robustly detect effects of fishing? ICES Journal of Marine Science 62:540-551. http://dx.doi.org/10.1016/ j.icesjms. 2004.12.012

Gerstenfeld, M. 1998. Judaism, environmentalism, and the environment: mapping and analysis. Jerusalem Institute for Israel Studies, Jerusalem, Israel.

Goyert, W., R. Sagarin, and J. Annala. 2010. The promise and pitfalls of Marine Stewardship Council certification: Maine lobster as a case study. Marine Policy 34:1103-1109. http://dx.doi. org/10.1016/j.marpol.2010.03.010

Gulbrandsen, L. H. 2006. Creating markets for eco-labelling: are consumers insignificant? International Journal of Consumer Studies 30:477-489. http://dx.doi.org/10.1111/j.1470-6431.2006.00534. $\underline{\mathrm{x}}$

Gullison, R. E. 2003. Does forest certification conserve biodiversity? Oryx 37:153-165. [online] URL: http://www.cbd.int/ doc/articles/2003/a-00137.pdf

Hirschman, A. O. 1970. Exit, voice, and loyalty: responses to decline in firms, organizations, and states. Harvard University Press, Cambridge, Massachusetts, USA.

Howard, P. H., and P. Allen. 2010. Beyond organic and fair trade? An analysis of ecolabel preferences in the United States. Rural Sociology 75:244-269. http://dx.doi.org/10.1111/j.1549-0831.2009.00009. $\underline{\mathrm{x}}$

Imai, C. M., D. J. Burnett, and J. T. Dwyer. 2009. The influence of culture and on food choices. CRC Press, Boca Raton, Florida, USA.

Irvine, J., T. Nagasawa, K. B. Seong, N. Klovach, and L.-L. Low. 2010. North Pacific anadromous fish commission statistical yearbook 2010. NPAFC, Vancouver, British Columbia, Canada. [online] URL: http://www.npafc.org/publications/Statistical\% 20Yearbook/Data/2010/2010page.htm

Jacquet, J. L., and D. Pauly. 2008. Trade secrets: renaming and mislabeling of seafood. Marine Policy 32:309-318. http://dx.doi. org/10.1016/j.marpol.2007.06.007

Jacquet, J., D. Pauly, D. Ainley, S. Holt, P., Dayton, and J. Jackson. 2010. Seafood stewardship in crisis. Nature 467:28-29. http://dx. doi.org/10.1038/467028a

Jordan, A., R. K. W. Wurzel, A. Zito, and L. Brückner. 2004. Consumer responsibility-taking and ecolabelling schemes in Europe. Pages 161-180 in M. Micheletti, A. Follesdal, and D. Stolle, editors. Politics, products, and markets: exploring political consumerism past and present. Transaction Publishers, New Brunswick, Canada.

Kaiser, M. J., and G. Edward-Jones. 2006. The role of ecolabeling in fisheries management and conservation. Conservation Biology 20:392-398. http://dx.doi.org/10.1111/j.1523-1739.2006.00319.x
Kemmerly, J. D., and V. Macfarlane. 2009. The elements of a consumer-based initiative in contributing to positive environmental change: Monterey Bay Aquarium's Seafood Watch program. Zoo Biology 28:398-411. http://dx.doi. org/10.1002/zoo.20193

Levin, P. S., and A. Dufault. 2010. Eating up the food web. Fish and Fisheries 11:307-312. http://dx.doi.org/10.1111/ j.1467-2979.2010.00355.x

Liu, X., M. E. McGarrity, and Y. Li. 2012. The influence of traditional Buddhist wildlife release on biological invasions. Conservation Letters. 5:107-114. http://dx.doi.org/10.1111/ j.1755-263X.2011.00215.X

Macht, D. I. 1953. An experimental pharmacological appreciation of Leviticus XI and Deuteronomy XIV. Bulletin of the History of Medicine 27:444-450.

Marjokorpi, A., and K. Ruokolainen. 2003. The role of traditional forest gardens in the conservation of tree species in West Kalimantan, Indonesia. Biodiversity and Conservation 12:799-822. http://dx.doi.org/10.1023/A:1022487631270

McNeely, J. A., and D. Pitt. 1985. Culture and conservation. Longwood, Wolfeboro, New Hampshire, USA.

Meigs, A. 1987. Food as a cultural construction. Food and Foodways 2:341-357. http://dx.doi.org/10.1080/07409710.1987.9961926

Monterey Bay Aquarium. 2011. Turning the tide. The state of seafood. Monterey Bay Aquarium, Monterey, California, USA. [online] URL: http://www.seafoodwatch.org/cr/cr_seafoodwatch/ content/media/MBA SeafoodWatch StateofSeafoodReport.pdf

Palmer, M. 2010. Religion, culture and diet. Pages 227-234 in J. D'Silva and J. Webster, editors. The meat crisis: developing more sustainable production and consumption. Earthscan, London, UK.

Palmer, M., and V. Finlay. 2003. Faith in conservation: new approaches to religions and the environment. World Bank, Washington, D.C., USA. [online] URL: http://siteresources. worldbank.org/INTBIODIVERSITY/214584-1112712965549/20480342/ FaithInConservationNewApproachesPreface2003.pdf

Parker, R. W. R., and P. H. Tyedmers. 2012. Uncertainty and natural variability in the ecological footprint of fisheries: a case study of reduction fisheries for meal and oil. Ecological Indicators 16:76-83. http://dx.doi.org/10.1016/j.ecolind.2011.06.015

Pauly, D., V. Christensen, J. Dalsgaard, R. Froese, and F. Torres, Jr. 1998. Fishing down marine food webs. Science 279:860-863. http://dx.doi.org/10.1126/science.279.5352.860

Pelletier, N., E. Audsley, S. Brodt, T. Garnett, P. Henriksson, A. Kendall, K. J. Kramer, D. Murphy, T. Nemecek, and M. Troell. 2011. Energy intensity of agriculture and food systems. Annual Review of Environment and Resources 36:223-246. http://dx.doi. org/10.1146/annurev-environ-081710-161014

Samhouri, J. F., P. S. Levin, and C. J. Harvey. 2009. Quantitative evaluation of marine ecosystem indicator performance using food web models. Ecosystems 12:1283-1298. http://dx.doi.org/10.1007/ s10021-009-9286-9 
Schau, E. M., H. Ellingsen, A. Endal, and S. A. Aanondsen. 2009. Energy consumption in the Norwegian fisheries. Journal of Cleaner Production 17:325-334. http://dx.doi.org/10.1016/j. jclepro.2008.08.015

Seafood Watch. 2012. Developing Seafood Watch recommendations. Monterey Bay Aquarium, Monterey, California, USA. [online] URL: http://www.seafoodwatch.org/cr/cr_seafoodwatch/content/ media/mba seafoodwatch recommendationprocess.pdf

Shelton, P. A. 2009. Eco-certification of sustainably managed fisheries: redundancy or synergy? Fisheries Research 100:185-190. http://dx.doi.org/10.1016/j.fishres.2009.08.004

Soler, J. 1997. The semiotics of food in the Bible. Pages 55-66 in C. Counihan and P. Van Esterik, editors. Food and culture: a reader. Routledge, New York, New York, USA.

Sønderskov, K. M., and C. Daugbjerg. 2011. The state and consumer confidence in eco-labeling: organic labeling in Denmark, Sweden, the United Kingdom and the United States. Agriculture and Human Values 28:507-517. http://dx.doi. org/10.1007/s10460-010-9295-5

Starobin, S., and E. Weinthal. 2010. The search for credible information in social and environmental global governance: the kosher label. Business and Politics 12:3. http://dx.doi. org/10.2202/1469-3569.1322

Steinberg, P. F. 2009. Institutional resilience amid political change: the case of biodiversity conservation. Global Environmental Politics 9:61-81. http://dx.doi.org/10.1162/ glep.2009.9.3.61

Stern, L. 2004. How to keep kosher. A comprehensive guide to understanding Jewish dietary laws. Harpers Collins, New York, New York, USA.

Teisl, M. F., B. Roe, and R. L. Hicks. 2002. Can eco-labels tune a market? Evidence from dolphin-safe labeling. Journal of Environmental Economics and Management 43:339-359. http://dx. doi.org/10.1006/jeem.2000.1186

Tyedmers, P. 2004. Fisheries and energy use. Encyclopedia of energy 2:683-693. http://dx.doi.org/10.1016/B0-12-176480-X/00204-7

Tyedmers, P., and M. R. Parker. 2012. Fuel consumption and greenhouse gas emissions from global tuna fisheries: a preliminary assessment. ISSF Technical Report 2012-03. International Seafood Sustainbility Foundation, McLean, Virgina, USA. [online] URL: http://iss-foundation.org/wp-content/uploads/ downloads/2012/03/ISSF-2012-03-Fuel-consumption.pdf

Washington, S. 2008. Ecolabels and marine capture fisheries: current practice and emerging issues. Food and Agriculture Organization, Rome, Italy. [online] URL: http://www.fao.org/ docrep/013/i1948e/i1948e04.pdf

Webb, K. E. 2002. Voluntary codes: private governance, the public interest and innovation. Carleton Research Unit for Innovation, Ottawa, Ontario, Canada.

Weber, C. L., and H. S. Matthews. 2008. Food-miles and the relative climate impacts of food choices in the United States. Environmental Science and Technology 42:3508-3513. http://dx. doi.org/10.1021/es702969f
Welfeld, I. H. 1996. Why kosher?: an anthology of answers. Jason Aronson, Lanham, Maryland, USA. 